\title{
Cyclin DI A870G polymorphism and the risk of colorectal cancer and adenoma
}

\author{
ES Schernhammer ${ }^{*, 1,2,3}$, GJ Tranah ${ }^{4,5}$, E Giovannucci ${ }^{1,5,6}$, AT Chan ${ }^{1,7}$, J Ma', GA Colditz ${ }^{1,5,6,8}$, DJ Hunter ${ }^{1,4}$, \\ WC Willett ${ }^{1,4,6}$ and CS Fuchs ${ }^{1,9}$
}

'Channing Laboratory, Department of Medicine, Brigham and Women's Hospital and Harvard Medical School, I8I Longwood Avenue, Boston, MA 0211 5, USA; ${ }^{2}$ Ludwig Boltzmann - Institute for Applied Cancer Research, KFJ-Spital, Vienna, Austria; ${ }^{3}$ Applied Cancer Research - Institute for Translational Research Vienna (ACR - ITR VIEnna), Vienna, Austria; ${ }^{4}$ Department of Epidemiology, Harvard School of Public Health, Boston, MA, USA; ${ }^{5}$ Harvard Center for Cancer Prevention, Boston, MA, USA; ${ }^{6}$ Department of Nutrition, Harvard School of Public Health, Boston, MA, USA; ${ }^{7}$ Gastrointestinal Unit, Massachusetts General Hospital, Boston, MA, USA; ${ }^{8}$ Epidemiology Program, Dana-Faber/Harvard Cancer Center, Boston, MA, USA; ${ }^{9}$ Department of Adult Oncology, Dana-Farber Cancer Institute, Boston, MA, USA

Cyclin DI (CCND I) plays a key role in cell cycle control, particularly in the transition from $\mathrm{G}$, to S phase, which is regulated by cyclindependent kinases. A common adenine to guanine polymorphism (A870G) in the CCNDI gene has been associated with a longer-life protein and an increased risk of colorectal cancer and adenoma in some studies. Among subjects with hereditary nonpolyposis colorectal cancer, the A870G polymorphism has also been associated with a younger age of onset of colorectal cancer. We analysed I8I colorectal cancer cases and 475 matched controls and 524 adenoma cases and 517 matched controls within women in the Nurses' Health Study (NHS) cohort, 17I colorectal cancer cases and 347 matched controls and 372 adenoma cases and 7I2 matched controls nested within men in the Health Professionals' Follow-Up Study (HPFS) cohort, and 258 colorectal cancer cases and 415 matched controls within men in the Physicians' Health Study (PHS) cohort to assess the risk associated with the CCND I A870G genotype. Moreover, we assessed whether CCNDI genotype modified the effect of a sporadic (nonsyndromic) family history of colorectal cancer as well as the effect of other dietary and lifestyle risk factors for colorectal cancer and adenoma. In all cohorts combined, the CCND I polymorphism did not show statistically significant associations to risk of colorectal cancer (odds ratio (OR) for A allele carriers, I.04; 95\% confidence interval (95\% Cl), 0.82- I.32) or adenoma (OR, 0.96; 95\% Cl, 0.79- I. I 8). The CCNDI A870G genotype was associated with a modest, although nonsignificantly elevated risk of colorectal cancer (OR, I.59; 95\% Cl, 0.98-2.57) in women. In contrast, the polymorphism was not associated with increased risk of adenoma in either men or women. Among participants with the A870G genotype, a family history of colorectal cancer conferred a substantially greater risk of colorectal cancer in the women $(P$ for interaction $=0.06)$ and adenoma in the men $(P$ for interaction $=0.02)$. Current postmenopausal hormone $(\mathrm{PMH})$ use was associated with a significant reduction in the risk of colorectal cancer and adenoma among women with the $A 870 \mathrm{G}$ genotype, whereas there was no effect of PMH use among those with the GG genotype. The CCNDI polymorphism appeared to confer a modest elevation in the risk of colorectal cancer among women. Moreover, the A870G genotype may enhance the protective effect of postmenopausal oestrogen use on the development of colorectal neoplasia.

British Journal of Cancer (2006) 94, 928-934. doi: I 0.1038/sj.bjc.6603007 www.bjcancer.com

Published online 2I February 2006

(c) 2006 Cancer Research UK

Keywords: cyclin D; CCND I; A870D; polymorphism; colorectal cancer; colorectal adenoma

Cyclin D1 (CCND1) is a protein that plays a key role in cell cycle control, particularly in the transition from $G_{1}$ to $S$ phase, which is regulated by cyclin-dependent kinases (Sherr, 1996). The overexpression of the CCND1 gene occurs in more than one-third of all colorectal cancers (Arber et al, 1996) and adenoma (Weinstein et al, 1997), and expression of an antisense CCND1 cDNA

*Correspondence: Dr ES Schernhammer, Channing Laboratory, Department of Medicine, Brigham and Women's Hospital and Harvard Medical School, 181 Longwood Avenue, Boston, MA 02115, USA; E-mail: eva.schernhammer@channing.harvard.edu

Received 13 October 2005; revised 19 January 2006; accepted 23 January 2006; published online 2I February 2006 suppresses the growth of colon cancer cells in animal models (Arber et al, 1997).

Cyclin D1 mRNA is alternatively spliced between exons 4 and 5 to generate two transcripts, which may be concurrently transcribed in various human tissues (Betticher et al, 1995). A common $\mathrm{G}$ to A polymorphism at codon 242 on exon 4 in the CCND1 gene has been shown to modulate splicing of the CCND1 transcript (Betticher et al, 1995). The dominant A allele preferentially generates the truncated transcript (Weinstein et al, 1997; Sawa et al, 1998), which encodes a cyclin D1 protein with a longer halflife. This accumulation of cyclin D1 in the cell may promote cell proliferation and the subsequent development of colorectal cancer.

Previous studies have had inconsistent results for an association of the CCND1 A870G polymorphism with bladder cancer 
(Cortessis et al, 2003; Wang et al, 2003b; Berman et al, 2004; Ito et al, 2004), endometrial cancer (Kang et al, 2005), breast cancer (Grieu et al, 2003; Krippl et al, 2003; Shu et al, 2005), head and neck cancer (Zheng et al, 2001), gastric and oesophageal cancer (Wang et al, 2003c; Zhang et al, 2003a), hepatocellular carcinoma (Zhang et al, 2003b), lung cancer (Qiuling et al, 2003), and prostate cancer (Koike et al, 2003; Wang et al, 2003a). The strongest evidence, to date, has linked the CCND1 A870G polymorphism with an increased risk of colorectal cancer and adenoma in many (Kong et al, 2000, 2001; Bala and Peltomaki, 2001; Porter et al, 2002) though not all studies (McKay et al, 2000). Moreover, the CCND1 A870G genotype (Kong et al, 2000) or the presence of the variant truncated CCND1 transcript (preferentially encoded by the A870G genotype) (Bala and Peltomaki, 2001) was associated with a younger age of cancer onset in subjects with hereditary nonpolyposis colorectal cancer (HNPCC). Nonetheless, few studies have examined the influence of the genotype among subjects with a common family history of colorectal cancer (e.g., one or two affected first-degree relatives), and few have assessed potential interactions between dietary and other environmental risk factors and CCND1 genotype.

We therefore examined the influence of the CCND1 A870G polymorphism on the risk of colorectal cancer and adenoma in three large prospective cohort studies, the Nurses' Health Study (NHS), the Health Professionals' Follow-Up Study (HPFS), and the Physicians' Health Study (PHS). Using banked blood specimens and regularly updated data on dietary and lifestyle risk factors, we assessed whether the influence of these environmental factors was modified by the CCND1 polymorphism.

\section{MATERIALS AND METHODS}

\section{Study subjects}

The NHS is an ongoing prospective study of 121700 US female registered nurses. Details of the design and follow-up of this cohort have been described previously (Chen et al, 1998). Briefly, at enrollment in 1976, the participants, who were 30-55 years old, completed a mailed questionnaire providing information on risk factors for cancer and cardiovascular disease. Biennially, updated exposure and disease information is collected by mail, including reports of endoscopy and polyp diagnosis. Self-reported diagnoses of colorectal cancer and adenoma are confirmed through histopathological reports reviewed by a study investigator. From 1989 to 1990 , blood samples were collected from 32826 of the NHS participants. For the analysis of cancers, we confirmed 197 cases of colorectal cancer diagnosed after blood collection through 1 June 2000 among eligible women. In all, 590 women who were free from cancer at the time of case assessment were selected as controls for the cancer cases and matched on year of birth and month of blood draw.

Eligible women for the selection of either an adenoma case or adenoma control were those women who reported a sigmoidoscopy and/or colonoscopy after providing a blood sample and were free from inflammatory bowel disease, a polyposis syndrome, or diagnosed cancer (except nonmelanoma skin cancer). As in previous studies (Chan et al, 2004), to avoid detection bias, we defined adenoma cases as one or more pathology-verified adenoma less than $60 \mathrm{~cm}$ from the anus. In both the NHS and HPFS, although we asked participants if they underwent sigmoidoscopy or colonoscopy, we did not ask them to specify the type of procedure. Thus, during the study period, for the analysis of adenoma in both cohorts, we assumed that a substantial portion of all procedures were sigmoidoscopies, which encompass only examination of the distal colon and rectum. One control was matched to each case according to year of birth, month of blood draw, fasting status, time period of endoscopy (within 2 years), and routine screening, gastrointestinal symptoms, or family history of colorectal cancer as indication(s) for endoscopy. A total of 557 cases and 557 matched controls were identified. Subsequently, one colon polyp case was identified as hyperplastic and removed from the final analysis, which included 556 cases and 557 controls.

The HPFS began in 1986 when 51529 US male dentists, optometrists, osteopaths, podiatrists, pharmacists, and veterinarians, aged 40-75 years, responded to a mailed questionnaire (Giovannucci et al, 1993). These men provided baseline information on age, marital status, height and weight, ancestry, medications, smoking history, medical history, physical activity, and diet. Exposure and medical history information are updated every 2 years. When a participant reported a diagnosis of colorectal adenoma on the follow-up questionnaires, we asked for permission to acquire the relevant medical records. All cases in this analysis were confirmed through histopathologic reports reviewed by a study investigator. Blood samples were collected between 1993 and 1994 from 18025 participants, among whom 367 had been diagnosed with adenomatous polyps between 1986 and 1994 and were confirmed by medical records. To be eligible for selection as a case or control, a person must have completed a valid dietary questionnaire in 1986, supplied a blood sample, and have undergone sigmoidoscopy or colonoscopy after 1986, and not have had a cancer diagnosis, excluding nonmelanoma skin cancer, before the date of endoscopy. A total of 736 men who were free from diagnosed polyps at the time of case assessment were selected as controls and matched to each case on year of birth, whether they had had a previous endoscopy, and year of endoscopy. Subsequently, nine controls were identified as cases, so the final set included 376 cases and 725 controls. For the analysis of cancers, we confirmed 182 cases of colorectal cancer diagnosed after blood collection through 1 June 2002 among eligible men. In total, 364 men who were free from cancer at the time of case assessment were selected as controls for the cancer cases and matched on year of birth and month of blood draw.

The PHS is a randomised, double-blind trial of aspirin and $\beta$ carotene among 22071 predominantly Caucasian-American male physicians, 40-84 years of age in 1982. Blood samples were collected at baseline, in 1982, from 14916 (68\%) of the randomised physicians. The men were subsequently followed for incident cancer through annual mailed questionnaires. By the year 2000, 272 cases of colorectal cancer were identified and confirmed using medical records. Men who were free from diagnosed cancer at the time of cancer ascertainment $(n=456)$ were selected as controls, and were matched on age ( \pm 1 year; up to \pm 5 years for older men) and on smoking history at baseline (current, former, and neversmokers).

\section{Sample collection}

In both the NHS and HPFS, venous blood samples were separated into plasma, buffy coat and red blood cells and stored in liquid nitrogen. Genomic DNA was extracted from whole blood samples (PHS) or from $50 \mu \mathrm{l}$ buffy coat diluted with $150 \mu \mathrm{l}$ of phosphatebuffered saline and using the QIAmp (Qiagen Inc., Chatsworth, CA, USA) 96-spin blood protocol according to the manufacturer's instructions. Genomic DNA concentrations were calculated in 96-well format using PicoGreen technology (Molecular Probes, Eugene, OR, USA).

\section{Cyclin D genotype}

Genotyping of CCND1 was carried out using the TaqMan allelic discrimination system (Applied Biosystems, Foster City, CA, USA). TaqMan primers and probes are available upon request from the authors. Following polymerase chain reaction amplification, end point fluorescence was read with the Applied Biosystems 7900HT 
instrument and genotypes were assigned using Allelic Discrimination Software (Applied Biosystems SDS Software v.1.7a). Quality control (QC, 10\%) samples were included and each analysis included no DNA template controls. Laboratory personnel were blinded to QC and case-control status. In all, 1697 women from the NHS (524 colorectal adenoma cases and 517 matched controls as well as 181 colorectal cancer cases and 475 matched controls) were successfully genotyped, as well as 2275 men from the HPFS (372 colorectal adenoma cases and 712 matched controls as well as 171 colorectal cancer cases and 347 matched controls) and from the PHS (258 colorectal cancer cases and matched controls).

\section{Statistical analyses}

Adenoma risk was considered in relation to the CCND1 genotypes. Cyclin D1 A870G was categorised into the three genotypes (G/G, $\mathrm{G} / \mathrm{A}$, and $\mathrm{A} / \mathrm{A}$ ) and as noncarriers (i.e., the wild type, $\mathrm{G} / \mathrm{G}$ ) vs carriers of the variant $A$ allele $(A / A, G / A+A / A)$. We conducted analyses for all three cohorts separately and then combined analyses, pooling data from the NHS, HPFS, and PHS, with adjustment for age, gender, and body mass index (BMI). For analysis of the main effect of genotype, logistic regression was used to compute odds ratio (OR) and $95 \%$ confidence intervals (CIs), control for a variety of potentially confounding variables, and to test for geneenvironment interactions. Although the data sets were initially based on matched cases and controls, the stratified analyses required unconditional analysis. Moreover, conditional logistic regression yielded similar results as obtained when running unconditional logistic regression models, thus we report OR) derived from unconditional regression models throughout the manuscript. Specifically, analyses involving NHS, HPFS, and PHS cancer cases and controls were controlled for age, family history of colorectal cancer (NHS and HPFS only), smoking history, aspirin use, BMI, postmenopausal status and postmenopausal hormone (PMH) use (NHS only), physical activity, and intake of red meat, folic acid and alcohol, and history of previous endoscopy (HPFS only). For colorectal adenoma, separate analyses for men and women using unconditional logistic regression were controlled for age, history of previous endoscopy, year of endoscopy, family history of colorectal cancer, smoking history, aspirin use, BMI, $\mathrm{PMH}$ use among postmenopausal women (NHS only), physical activity, and intake of red meat, charred meat, folate, and alcohol. In subanalyses, men and women in the adenoma groups were combined for gene-environment interactions and were controlled for age, sex, and family history of colorectal cancer. Analyses involving PHS cancer cases and controls were controlled for age, smoking status, aspirin use, BMI, physical activity, and intake of red meat, vitamins, and alcohol.

The effects of various dietary and lifestyle exposures on colon cancer and adenoma risk were tested in conjunction with CCND1 genotype. In the NHS colorectal cancer group, CCND1 genotypes were analysed in combination with micrograms $(\mu \mathrm{g})$ per day of folate including supplements $(\leqslant 310,>310)$, milligrams $(\mathrm{mg})$ per day of vitamin B6 pyridoxine $(\leqslant 2.5,>2.5)$ and grams $(\mathrm{g})$ per day of methionine $(\leqslant 1.84,>1.84)$, based on median distributions in the control population, regular aspirin intake (yes, no), family history of colorectal cancer (yes, no), pack-years of smoking before age $30(0, \leqslant 10,>10)$, g per day of alcohol $(<30, \geqslant 30)$, age at diagnosis $(\leqslant 65,>65)$, and PMH use among postmenopausal women (never/past, current). In subanalyses, we stratified on the stage of disease (stage I (muscle only) vs stages II and III combined (pericolic or perirectal tissue, with or without involvement of lymph nodes)) and site (colon $v s$ rectum). In the NHS adenoma group, CCND1 genotypes were analysed in combination with $\mu \mathrm{g}$ per day of folate including supplements $(\leqslant 310,>310)$, mg per day of vitamin B6 (pyridoxine), and g per day of methionine $(\leqslant 1.84$, $>1.84$ ), based on median distributions in the control population, family history of colorectal cancer (yes, no) both alone and in conjunction with adenoma size (small/large), pack-years of smoking ( 0 years, $<25$ years, $\geqslant 25$ years), g per day of alcohol $(<30, \geqslant 30)$, age at diagnosis $(\leqslant 60,>60)$, regular aspirin intake (yes, no), PMH use among postmenopausal women (never/past, current), site (proximal vs distal), and size (large $v s$ small) of adenoma. In the HPFS adenoma group, CCND1 genotypes were analysed in combination with $\mu \mathrm{g}$ per day of folate including supplements $(\leqslant 338,339-496, \geqslant 497)$, and g per day of methionine $(\leqslant 2.15,>2.15)$, based on median distributions in the control population, regular aspirin intake (yes, no), age at diagnosis $(\leqslant 60$, $>60$ ), pack-years of smoking ( 0 years, $<25$ years, $\geqslant 25$ years), g per day of alcohol $(<5,5-30,>30)$, and family history of colorectal cancer (yes, no). In subanalyses, we stratified on age at diagnosis $(\leqslant 60,>60)$ and site (proximal $v s$ distal), and size (large $v s$ small) of adenoma. In the HPFS cancer group, CCND1 genotypes were analysed in combination with $\mu \mathrm{g}$ per day of folate including supplements $(\leqslant 338,339-496, \geqslant 497)$, and g per day of methionine $(\leqslant 2.15,>2.15)$, based on median distributions in the control population, regular aspirin intake (yes, no), age at diagnosis $(\leqslant 60$, $>60$ ), pack-years of smoking ( 0 years, $<25$ years, $\geqslant 25$ years), $g$ per day of alcohol $(<5,5-30,>30)$, and family history of colorectal cancer (yes, no). In subanalyses, we stratified on the stage of disease (advanced $v s$ not) and site (colon $v s$ rectum). In the PHS colorectal cancer group, CCND1 genotypes were analysed in combination with smoking (never, past, current), vitamin intake (never, past, current), aspirin assignment (yes, no), age at diagnosis $(\leqslant 55,>55)$, site (rectum $v s$ colon), alcohol intake in drinks per day $(1, \geqslant 1)$, and age $(\leqslant 55,>55)$. Exposure information for the NHS was updated from 1990, 1992, 1994, 1996 to 1998. Exposure information for the HPFS and PHS was collected at baseline in 1986 and 1982, respectively.

Statistical tests for interaction was based on the Wald test for the crossproduct term in a model containing the main effects of genotype and exposure variable as continuous variables. All $P$-values are two-sided. All statistical analyses were carried out using the SAS 8.2 statistical package (SAS Institute, Cary, NC, USA).

\section{RESULTS}

\section{Dietary and lifestyle factors}

A recent case-control study (Tranah et al, 2005) examined whether the risk factors for colorectal adenoma and cancer were similar in the cases and controls that provided blood samples compared to previous observations for each cohort. For all cohorts, the risk patterns observed for adenoma and cancer cases in this sample were largely similar to those reported for the entire cohort, as reported previously (Giovannucci et al, 1993; Giovannucci et al, 2003, 1994a, b). Only for the PHS-nested casecontrol study, the risk factors analysed were not associated with an increased risk of colorectal cancer.

\section{CCND1 polymorphism}

The CCND1 A allele frequency ranged from 53 to $56 \%$ in the NHS, HPFS, and PHS control populations and the genotype distributions were in Hardy-Weinberg equilibrium. The A allele frequency was slightly more frequent in our populations than in similar, white populations of previous reports $(42-43 \%)$ (Bala and Peltomaki, 2001; Le Marchand et al, 2003; Lewis et al, 2003).

In all cohorts combined, the CCND1 polymorphism did not show statistically significant associations to risk of colorectal cancer (odds ratio (OR), 1.04; 95\% CI, $0.82-1.32$ ) or adenoma (OR, 0.96; $95 \% \mathrm{CI}, 0.77-1.18$ ). Moreover, the risk associated with the homozygous AA genotype did not appear to differ materially from the heterozygous GA genotype (Table 1). The CCND1 A870G polymorphism appeared to confer a modest, although statistically 
insignificant, increase in the risk of colorectal cancer in women (OR, 1.59; 95\% CI, 0.98-2.57). In contrast, the variant genotype was not associated with risk of cancer or adenoma in men or risk of adenoma in women. In addition, CCND1 genotype did not confer a significant elevation in the risk for either large $(\geqslant 1 \mathrm{~cm}) v s$ small $(<1 \mathrm{~cm})$ adenoma in either cohort (data not shown).

We assessed whether the influence of CCND1 genotype varied for proximal as compared to distal colorectal cancers. The CCND1 A870G polymorphism appeared to confer an elevated risk for cancers in the distal colon or rectum (rectum to splenic flexure) (OR, 2.84; 95\% CI, 1.27-6.33), but not for proximal cancers (splenic flexure to caecum) (OR, 1.26; 95\% CI, 0.61-2.60) in the women. In contrast, among men in the HPFS, we found similar risks for both proximal (OR, 1.09; 95\% CI, 0.54-2.19) and distal cancers (OR, $0.67 ; 95 \% \mathrm{CI}, 0.37-1.21$ ). Data on cancer location within the bowel were not available from the PHS cohort. Previous studies reported a younger age of onset for colorectal cancer for subjects with HNPCC who possessed the AA or GA CCND1 genotype or the presence of the variant truncated CCND1 transcript (preferentially encoded by the A870G genotype) (Kong et al, 2000; Bala and Peltomaki, 2001). We therefore examined whether CCND1 genotype modified the influence of a common family history of colorectal cancer (i.e., a history in one or more first-degree relatives) on cancer and adenoma risk (Table 2). Among female participants with the GG genotype, a family history of colorectal cancer in one or more first-degree relatives was not associated with a statistically significant elevation in colorectal cancer risk. In contrast, for participants with the GA or AA genotype, a family history was associated with a statistically significant risk of colorectal cancer (multivariate OR, 1.95, 95\% CI, 1.13-3.34). After adjusting for other covariates, the influence of genotype on the relation between family history and cancer risk was at the border of statistical significance ( $P$ for interaction $=0.06$ ). However, in this cohort of women, we found no material interaction between genotype, family history and adenoma risk.

Similarly, among those with a family history, there was an increased risk from the GA or AA genotype, compared to those with the wild type. Among men in the HPFS, the influence of CCND1 genotype on the relation between family history and adenoma risk in the HPFS was statistically significant ( $P$ for interaction $=0.02$ ). Whereas family history conferred no significant influence on adenoma risk among men with the GG genotype, family history was associated with a significantly increased adenoma risk (multivariate OR, 2.28, 95\% CI, 1.32-3.95) among men with the GA or AA genotypes. Nonetheless, among men in the HPFS, we found no significant interaction between genotype, family history, and colorectal cancer risk (data on family history were not available from the PHS cohort). In addition, we examined whether age at onset of disease influenced the overall association between the genotype and colorectal cancer or adenomas. In these analyses, we observed a higher risk of colorectal cancer among women who carried one or two copies of the A allele and who had a diagnosis of colorectal cancer at a later age (i.e., at or above age 65 years, as opposed to before age 65 years; AA + AG allele; RR, 2.33; 95\% CI, 1.02-5.28). Similar risk increases were not observed for colorectal adenomas among women, or among men.

We also assessed the associations of several dietary and lifestyle factors with risk of colorectal cancer or adenoma stratified by CCND1 genotype. In analyses of both cancer and adenoma, the influence of BMI, smoking, aspirin use, and intakes of folate, red meat, and alcohol did not differ significantly according to CCND1 genotype (in the PHS, folate intake was not assessed). However, among postmenopausal women, the inverse relation between postmenopausal oestrogen use and colorectal cancer and adenoma risk appeared to be limited to the A870G polymorphism (Table 3). Among women with the GG genotype, current PMH use did not significantly influence the risk of colorectal cancer or adenoma.
Table I Associations between CCND I A870G genotype and colorectal carcinoma and adenoma risk in the NHS, HPFS, and PHS

\begin{tabular}{lccc}
\hline CCNDI G to A & Cases (\%) & Controls (\%) & OR (95\% CI) \\
\hline Cancer overall & \multicolumn{3}{c}{} \\
N & 610 & 1237 \\
GG & $125(20.5)$ & $264(21.3)$ & $1.0^{\mathrm{a}}$ \\
AG & $311(51)$ & $593(48)$ & $1.03(0.78-1.36)$ \\
AA & $174(28.5)$ & $380(30.7)$ & $1.12(0.90-1.41)$ \\
AA+AG & $485(79.5)$ & $973(78.7)$ & $1.04(0.82-1.32)$ \\
P for trend & & & 0.64
\end{tabular}

Adenoma overall

$\mathrm{N}$

GG

AG

AA

$\mathrm{AA}+\mathrm{AG}$

$P$ for trend

896

$187(20.9)$

44I (49.2)

$268(29.9)$

$709(79.1)$

$41(19.6)$

$614(50)$

$374(30.4)$

$988(80.4)$

$0.95(0.77-1.18)$

$1.00(0.78-1.28)$

$0.96(0.79-1.18)$

0.99

NHS cancer

$\mathrm{N}$

GG

AG

181

$29(16)$

$95(52.5)$

AA

57 (31.5)

$\mathrm{AA}+\mathrm{AG}$

152 (84)

$P$ for trend

524

NHS adenoma

$\mathrm{N}$

GG

AG

$108(20.6)$

$265(50.6)$

AA

AA+AG

$P$ for trend

I5I (28.8)

$416(79.4)$

475

$110(23.2)$

$224(47.2)$

|4| (29.7)

365 (76.8)

1.0

$1.61(0.96-2.68)$

$1.55(0.90-2.69)$

$1.59(0.98-2.57)$

0.16

\begin{tabular}{|c|c|c|c|}
\hline \multicolumn{4}{|l|}{ PHS cancer ${ }^{c}$} \\
\hline$N$ & 258 & 415 & \\
\hline GG & $56(21.7)$ & $85(20.5)$ & $1.0^{\mathrm{a}}$ \\
\hline AG & $136(52.7)$ & $203(48.9)$ & $1.02(0.68-1.55)$ \\
\hline AA & $66(25.6)$ & $127(30.6)$ & $0.80(0.5 \mid-1.27)$ \\
\hline$A A+A G$ & $202(78.3)$ & $330(79.5)$ & $0.94(0.64-1.39)$ \\
\hline \multicolumn{4}{|l|}{ HPFS cancer ${ }^{b}$} \\
\hline$N$ & 171 & 347 & \\
\hline GG & $40(23.4)$ & $69(19.9)$ & $1.0^{\mathrm{a}}$ \\
\hline$A G$ & $80(46.8)$ & $166(47.8)$ & $0.86(0.53-1.40)$ \\
\hline AA & $51(29.8)$ & $112(32.3)$ & $0.81(0.48-1.38)$ \\
\hline$A A+A G$ & $131(76.6)$ & $278(80.1)$ & $0.84(0.53-1.33)$ \\
\hline$P$ for trend & & & 0.45 \\
\hline \multicolumn{4}{|c|}{ HPFS adenomac } \\
\hline$N$ & 372 & 712 & \\
\hline GG & $79(2 \mid .2)$ & |4| (19.8) & $1.0^{\mathrm{a}}$ \\
\hline$A G$ & $176(47.3)$ & $348(48.9)$ & $0.96(0.68-1.36)$ \\
\hline AA & $117(31.5)$ & $223(31.3)$ & $0.91(0.63-1.33)$ \\
\hline$A A+A G$ & $293(78.8)$ & $57 \mid(80.2)$ & $0.94(0.68-1.31)$ \\
\hline$P$ for trend & & & 0.61 \\
\hline
\end{tabular}

CCNDI = cyclin DI; Cl= confidence interval; HPFS = Health Professionals' FollowUp Study; NHS = Nurses' Health Study; OR = odds ratio; PHS = Physicians' Health Study. ${ }^{a}$ Reference group. 'Unconditional logistic regression adjusted for age, family history of colorectal cancer, smoking history, aspirin use, BMI, PMH use, physical activity, and intake of red meat, charred meat, folate, and alcohol. 'Unconditional logistic regression adjusted for age, previous endoscopy, year of endoscopy, family history of colorectal cancer, pack-years smoking, aspirin use, BMI, PMH use (NHS only), physical activity, and intake of red meat, charred meat, folate, and alcohol.

However, among women with the GA or AA genotype, current postmenopausal oestrogen use was associated with a significant reduction in the risk of colorectal cancer when compared to never or former users (multivariate OR, 0.57, 95\% CI, 0.35-0.92), although a test for statistical interaction was not significant. 
Table 2 Relationship between family history of colorectal cancer and risk of colorectal cancer and adenoma among postmenopausal women in the $\mathrm{NHS}$ and men in the HPFS, stratified by CCND I A870G genotype

\begin{tabular}{|c|c|c|c|c|c|}
\hline & \multicolumn{4}{|c|}{ Family history of colorectal cancer } & \multirow[b]{3}{*}{$\begin{array}{c}P \text { for } \\
\text { interaction }\end{array}$} \\
\hline & \multicolumn{2}{|r|}{ No } & \multicolumn{2}{|r|}{ Yes } & \\
\hline & $\begin{array}{l}\text { Casel } \\
\text { control }\end{array}$ & $\begin{array}{c}\text { OR } \\
\text { (reference) }\end{array}$ & $\begin{array}{l}\text { Casel } \\
\text { control }\end{array}$ & OR $(95 \% \mathrm{Cl})$ & \\
\hline \multicolumn{2}{|c|}{ NHS cancer ${ }^{2 *}$} & & & & 0.06 \\
\hline GG & $22 / 89$ & 1.0 & $7 / 21$ & $1.15(0.38-3.50)$ & \\
\hline GA/AA & $113 / 316$ & 1.0 & $31 / 45$ & $1.95(1.13-3.34)$ & \\
\hline \multicolumn{2}{|c|}{ NHS adenoma ${ }^{b}$} & & & & 0.77 \\
\hline GG & $75 / 76$ & 1.0 & $33 / 24$ & $1.77(0.84-3.72)$ & \\
\hline GA/AA & $295 / 338$ & 1.0 & $121 / 79$ & $1.85(1.31-2.61)$ & \\
\hline \multicolumn{2}{|c|}{ HPFS cancer $^{\mathrm{a}}$} & & & & 0.80 \\
\hline GG & $27 / 59$ & 1.0 & $13 / 10$ & $3.15(1.14-8.67)$ & \\
\hline GA/AA & 107/241 & 1.0 & $24 / 37$ & $1.44(0.80-2.57)$ & \\
\hline \multicolumn{2}{|c|}{ HPFS adenoma ${ }^{b}$} & & & & 0.02 \\
\hline GG & $74 / 126$ & 1.0 & $5 / 15$ & $0.52(0.17-1.60)$ & \\
\hline GA/AA & $262 / 543$ & 1.0 & $31 / 28$ & $2.28(1.32-3.95)$ & \\
\hline
\end{tabular}

$C C N D I=$ cyclin $\mathrm{DI} ; \mathrm{Cl}=$ confidence interval; HPFS = Health Professionals' FollowUp Study; NHS = Nurses' Health Study; OR=odds ratio. *Case and control numbers differ from total because of missing information on family history. a Unconditional logistic regression adjusted for age, PMH use (NHS only), smoking history, aspirin use, BMI, physical activity, and intake of red meat, charred meat, folate, and alcohol. bunconditional logistic regression adjusted for age, history of previous endoscopy, year of endoscopy, PMH use, aspirin use, BMI, physical activity, and intake of red meat, well-done meat, folic acid, alcohol, total calories, and caloric-adjusted total fat.

Similarly, among women with the GA or AA genotype, current postmenopausal oestrogen use was associated with a significant reduction in adenoma risk when compared to never or former users (multivariate OR, $0.63,95 \% \mathrm{CI}, 0.45-0.87$ ), although the test for interaction was not significant.

\section{DISCUSSION}

In the present study, the GA or AA CCND1 genotype was associated with a borderline significant increase in the risk of colorectal cancer only among women. In contrast, we found no association between CCND1 genotype and the risk of distal colorectal adenoma in either women or men. Notably, among postmenopausal women in the NHS, a reduced risk of colorectal cancer or adenoma associated with current oestrogen use was restricted to women with the GA or AA CCND1 genotype. Postmenopausal oestrogen conferred no benefit among women with GG genotype.

Our findings for colorectal cancer among women are consistent with those of Le Marchand et al and others, which found a similar increase in the risk of colorectal cancer among participants with the GA or AA genotype (Kong et al, 2000; Porter et al, 2002; Le Marchand et al, 2003). In contrast to a previous study of colorectal adenoma (Lewis et al, 2003), we did not find an association between CCND1 genotype and the risk of adenoma, although our analysis was limited to adenoma of the distal colon and rectum.

Previous studies suggest that the GA or AA genotype is associated with a younger age of onset for HNPCC. One of these studies found that patients with HNPCC who carried the GA or AA genotype developed colorectal cancer on average 11 years earlier than those with the wild type (Kong et al, 2000). However, we are unaware of any studies that have examined the interaction with a
Table 3 Relationship between PMH use and risk of colorectal cancer and adenoma among postmenopausal women in the NHS stratified by CCND I A870G genotype

\begin{tabular}{|c|c|c|c|c|c|}
\hline & \multicolumn{4}{|c|}{ Postmenopausal hormone use } & \multirow[b]{3}{*}{$\begin{array}{c}P \text { for } \\
\text { interaction }\end{array}$} \\
\hline & \multicolumn{2}{|c|}{ Never-past use } & \multicolumn{2}{|c|}{ Current use } & \\
\hline & $\begin{array}{c}\text { Casel } \\
\text { control }\end{array}$ & $\begin{array}{c}\text { OR } \\
\text { (reference) }\end{array}$ & $\begin{array}{l}\text { Casel } \\
\text { control }\end{array}$ & OR (95\% CI) & \\
\hline \multirow{3}{*}{$\begin{array}{c}\text { NHS cancer }{ }^{\mathrm{a}} \\
\text { GG } \\
\text { GA/AA }\end{array}$} & & & & & \multirow[t]{3}{*}{0.37} \\
\hline & $14 / 69$ & 1.0 & $13 / 30$ & $2.34(0.75-7.31)$ & \\
\hline & $95 / 181$ & 1.0 & $38 / 135$ & $0.57(0.35-0.92)$ & \\
\hline \multicolumn{3}{|c|}{ NHS adenoma ${ }^{b}$} & & & \multirow[t]{3}{*}{0.33} \\
\hline GG & $56 / 50$ & 1.0 & $36 / 34$ & $1.21(0.55-2.64)$ & \\
\hline GA/AA & $209 / 166$ & 1.0 & |50/189 & $0.63(0.45-0.87)$ & \\
\hline \multicolumn{6}{|c|}{$\begin{array}{l}\text { CCNDI = cyclin } \mathrm{DI} ; \mathrm{Cl}=\text { confidence interval; } \mathrm{NHS}=\text { Nurses' Health Study; } \\
\mathrm{OR}=\text { odds ratio; } \mathrm{PMH}=\text { postmenopausal hormone. 'Unconditional logistic regres- } \\
\text { sion adjusted for age, family history of colorectal cancer, smoking history, aspirin use, } \\
\mathrm{BMI} \text {, physical activity, and intake of red meat, charred meat, folate, and alcohol. } \\
\text { bUnconditional logistic regression adjusted for age, history of previous endoscopy, } \\
\text { year of endoscopy, family history of colorectal cancer, aspirin use, BMI, physical } \\
\text { activity, and intake of red meat, well-done meat, folic acid, alcohol, total calories, and } \\
\text { caloric-adjusted total fat. }\end{array}$} \\
\hline
\end{tabular}

sporadic (nonsyndromic) family history. In our study, the presence of at least one A allele substantially augmented the effect of a family history of colorectal cancer on the risk of colorectal cancer in the NHS and the risk of colorectal adenoma in the HPFS. However, we did not find similar interactions for colorectal adenoma in the NHS and colorectal cancer in the HPFS. Given that there was some residual risk for colorectal neoplasia among individuals with the GG group, it appears unlikely that the G-to-A polymorphism is one of the main components and main underlying mechanisms for some nonsyndromic cases of familial colorectal cancer.

Numerous studies observed a significant reduction in the risk of colorectal cancer and adenoma among PMH users (Serrano et al, 2004), including a previous analysis of our female cohort (Grodstein et al, 1998) and a large randomised trial of postmenopausal women (Chlebowski et al, 2004). Nonetheless, no study, to date, has examined whether CCND1 genotype modifies the influence of PMH use on colorectal cancer and adenoma risk. We found that the benefit associated with $\mathrm{PMH}$ use was restricted to those with GA or AA genotype. In the Shanghai Women's Breast Cancer Study, the increased risk of breast cancer associated with oestrogens was limited to women with the GA or AA genotype $(\mathrm{OR}=2.6)$ (Shu et al, 2005). In contrast, women with the GG genotype experienced no increased risk for breast cancer in association with $\mathrm{PMH}$ use $(\mathrm{OR}=0.8)$. In a second study, oral contraceptive use was associated with an increased risk of breast cancers with CCND1 overexpression, but was unrelated to those without CCND1 overexpression (Terry et al, 2002). These data suggest that the CCND1 GA or AA genotype may augment the various influences of oestrogen in decreasing the risk of colorectal cancer and adenoma as well as increasing the risk of breast cancer. In previous studies, CCND1 can bind directly to the oestrogen receptor, transactivate oestrogen response elements (Zhou et al, 2001), and regulate oestrogen-dependent enhancer activity (Zafonte et al, 2000).

The strengths of our study include its relatively large size, prospective design, detailed data on potential confounders, and high follow-up rate. In particular, we had a unique ability to examine a wide range of exposures and interaction with genotype. As participants were health professionals, the accuracy of self-reported data is likely to be high; information on many 
exposures, including endoscopy, has been validated previously (Willett et al, 1985; Rimm et al, 1990; Wolf et al, 1994). Moreover, because our study was nested within three larger, well-defined cohorts, control participants were sampled from the same population as case participants. Thus, our results are unlikely to be influenced by population stratification or selection bias. Another strength of our study is that we were able to look at both cancer and adenoma as end points. Moreover, our cancer cases were incident cases, which may be important if cyclin D affects survival, as suggested by Le Marchand et al (2003); a study which collected DNA after diagnosis may not be able to include fatal cancers.

Our study has several limitations. Firstly, we did not specify on our questionnaire, whether study participants underwent a colonoscopy or sigmoidoscopy. Thus, with regard to our analysis of adenoma, it is possible that some controls were not entirely free of proximal adenomatous polyps (that were beyond the reach of the flexible sigmoidoscope), thus potentially limiting the generalisability of our adenoma findings. Moreover, since we limited our analysis to adenoma within the reach of the flexible sigmoidoscope, we were unable to assess the association of genotype with the risk of proximal adenoma. However, for the analysis of colorectal cancer in our cohort of women, the risk associated with
A870G genotype was, in fact, greater for cancers of the distal colon and rectum than for more proximal lesions. Finally, even though our study is of fairly large size, it may still have been underpowered for certain gene-environment interactions.

In summary, our results suggest that the risk of both colorectal cancer and adenoma associated with a family history of colorectal cancer may be augmented by the CCND1 A870G genotype. Moreover, the A870G genotype appears to enhance the protective effect of postmenopausal oestrogen use on the development of colorectal neoplasia. Additional studies are warranted to confirm this potential interaction between CCND1 genotype and postmenopausal oestrogen use.

\section{ACKNOWLEDGEMENTS}

This work is supported by National Institutes of Health research Grants CA70817, CA87969, CA55075, CA42812, CA58684, and CA90598. We thank the participants of the Nurses' Health Study, the Health Professionals' Follow-up Study, and the Physicians' Health Study for their cooperation and participation. We are grateful to Hardeep Ranu for technical assistance.

\section{REFERENCES}

Arber N, Doki Y, Han EK, Sgambato A, Zhou P, Kim NH, Delohery T, Klein MG, Holt PR, Weinstein IB (1997) Antisense to cyclin D1 inhibits the growth and tumorigenicity of human colon cancer cells. Cancer Res 57: $1569-1574$

Arber N, Hibshoosh H, Moss SF, Sutter T, Zhang Y, Begg M, Wang S, Weinstein IB, Holt PR (1996) Increased expression of cyclin D1 is an early event in multistage colorectal carcinogenesis. Gastroenterology 110: $669-674$

Bala S, Peltomaki P (2001) CYCLIN D1 as a genetic modifier in hereditary nonpolyposis colorectal cancer. Cancer Res 61: 6041-6045

Berman DM, Wang Y, Liu Z, Dong Q, Burke LA, Liotta LA, Fisher R, Wu X (2004) A functional polymorphism in RGS6 modulates the risk of bladder cancer. Cancer Res 64: 6820-6826

Betticher DC, Thatcher N, Altermatt HJ, Hoban P, Ryder WD, Heighway J (1995) Alternate splicing produces a novel cyclin D1 transcript. Oncogene 11: $1005-1011$

Chan AT, Giovannucci EL, Schernhammer ES, Colditz GA, Hunter DJ, Willett WC, Fuchs CS (2004) A prospective study of aspirin use and the risk for colorectal adenoma. Ann Intern Med 140: 157- 166

Chen J, Giovannucci E, Hankinson SE, Ma J, Willett WC, Spiegelman D, Kelsey KT, Hunter DJ (1998) A prospective study of methylenetetrahydrofolate reductase and methionine synthase gene polymorphisms, and risk of colorectal adenoma. Carcinogenesis 19: $2129-2132$

Chlebowski RT, Wactawski-Wende J, Ritenbaugh C, Hubbell FA, Ascensao J, Rodabough RJ, Rosenberg CA, Taylor VM, Harris R, Chen C, AdamsCampbell LL, White E, Women's Health Initiative Investigators (2004) Estrogen plus progestin and colorectal cancer in postmenopausal women. N Engl J Med 350: 991 - 1004

Cortessis VK, Siegmund K, Xue S, Ross RK, Yu MC (2003) A case-control study of cyclin D1 CCND1 $870 \mathrm{~A} \rightarrow \mathrm{G}$ polymorphism and bladder cancer. Carcinogenesis 24: 1645-1650

Giovannucci E, Chen J, Smith-Warner SA, Rimm EB, Fuchs CS, Palomeque C, Willett WC, Hunter DJ (2003) Methylenetetrahydrofolate reductase, alcohol dehydrogenase, diet, and risk of colorectal adenomas. Cancer Epidemiol Biomarkers Prev 12: 970 -979

Giovannucci E, Colditz GA, Stampfer MJ, Hunter D, Rosner BA, Willett WC, Speizer FE (1994a) A prospective study of cigarette smoking and risk of colorectal adenoma and colorectal cancer in US women. $J$ Natl Cancer Inst 86: 192 - 199

Giovannucci E, Rimm EB, Stampfer MJ, Colditz GA, Ascherio A, Kearney J, Willett WC (1994b) A prospective study of cigarette smoking and risk of colorectal adenoma and colorectal cancer in US men. J Natl Cancer Inst 86: $183-191$
Giovannucci E, Stampfer MJ, Colditz GA, Rimm EB, Trichopoulos D, Rosner BA, Speizer FE, Willett WC (1993) Folate, methionine, and alcohol intake and risk of colorectal adenoma. J Natl Cancer Inst 85: $875-884$

Grieu F, Malaney S, Ward R, Joseph D, Iacopetta B (2003) Lack of association between CCND1 G870A polymorphism and the risk of breast and colorectal cancers. Anticancer Res 23: 4257-4259

Grodstein F, Martinez ME, Platz EA, Giovannucci E, Colditz GA, Kautzky M, Fuchs C, Stampfer MJ (1998) Postmenopausal hormone use and risk for colorectal cancer and adenoma. Ann Intern Med 128: 705-712

Ito $\mathrm{M}$, Habuchi T, Watanabe J, Higashi S, Nishiyama $\mathrm{H}$, Wang L, Tsuchiya N, Kamoto T, Ogawa O (2004) Polymorphism within the cyclin D1 gene is associated with an increased risk of carcinoma in situ in patients with superficial bladder cancer. Urology 64: 74-78

Kang S, Kim JW, Park NH, Song YS, Kang SB, Lee HP (2005) Cyclin D1 polymorphism and the risk of endometrial cancer. Gynecol Oncol 97: $431-435$

Koike H, Suzuki K, Satoh T, Ohtake N, Takei T, Nakata S, Yamanaka H (2003) Cyclin D1 gene polymorphism and familial prostate cancer: the AA genotype of A870G polymorphism is associated with prostate cancer risk in men aged 70 years or older and metastatic stage. Anticancer Res 23: $4947-4951$

Kong S, Amos CI, Luthra R, Lynch PM, Levin B, Frazier ML (2000) Effects of cyclin D1 polymorphism on age of onset of hereditary nonpolyposis colorectal cancer. Cancer Res 60: 249-252

Kong S, Wei Q, Amos CI, Lynch PM, Levin B, Zong J, Frazier ML (2001) Cyclin D1 polymorphism and increased risk of colorectal cancer at young age. J Natl Cancer Inst 93: 1106-1108

Krippl P, Langsenlehner U, Renner W, Yazdani-Biuki B, Wolf G, Wascher TC, Paulweber B, Weitzer W, Leithner A, Samonigg H (2003) The $870 \mathrm{G}>\mathrm{A}$ polymorphism of the cyclin D1 gene is not associated with breast cancer. Breast Cancer Res Treat 82: $165-168$

Le Marchand L, Seifried A, Lum-Jones A, Donlon T, Wilkens LR (2003) Association of the cyclin D1 A870G polymorphism with advanced colorectal cancer. JAMA 290: 2843-2848

Lewis RC, Bostick RM, Xie D, Deng Z, Wargovich MJ, Fina MF, Roufail WM, Geisinger KR (2003) Polymorphism of the cyclin D1 gene, CCND1, and risk for incident sporadic colorectal adenomas. Cancer Res 63: $8549-8553$

McKay JA, Douglas JJ, Ross VG, Curran S, Murray GI, Cassidy J, McLeod HL (2000) Cyclin D1 protein expression and gene polymorphism in colorectal cancer. Aberdeen Colorectal Initiative. Int J Cancer 88: 77-81 Porter TR, Richards FM, Houlston RS, Evans DG, Jankowski JA, Macdonald F, Norbury G, Payne SJ, Fisher SA, Tomlinson I, Maher ER (2002) 
Contribution of cyclin $\mathrm{d} 1$ (CCND1) and E-cadherin (CDH1) polymorphisms to familial and sporadic colorectal cancer. Oncogene 21: 1928-1933

Qiuling S, Yuxin Z, Suhua Z, Cheng X, Shuguang L, Fengsheng H (2003) Cyclin D1 gene polymorphism and susceptibility to lung cancer in a Chinese population. Carcinogenesis 24: 1499-1503

Rimm EB, Stampfer MJ, Colditz GA, Chute CG, Litin LB, Willett WC (1990) Validity of self-reported waist and hip circumferences in men and women. Epidemiology 1: 466-473

Sawa H, Ohshima TA, Ukita H, Murakami H, Chiba Y, Kamada H, Hara M, Saito I (1998) Alternatively spliced forms of cyclin D1 modulate entry into the cell cycle in an inverse manner. Oncogene 16: 1701-1712

Serrano D, Lazzeroni M, Decensi A (2004) Chemoprevention of colorectal cancer: an update. Tech Coloprotocol 8: s248-s252

Sherr CJ (1996) Cancer cell cycles. Science 274: 1672-1677

Shu XO, Moore DB, Cai Q, Cheng J, Wen W, Pierce L, Cai H, Gao Y, Zheng W (2005) Association of cyclin D1 genotype with breast cancer risk and survival. Cancer Epidemiol Biomarkers 14: 91-97

Terry MB, Gammon MD, Schoenberg JB, Brinton LA, Arber N, Hibshoosh H. (2002) Oral contraceptive use and cyclin D1 overexpression in breast cancer among young women. Cancer Epidemiol Biomarkers 11: $1100-1103$

Tranah GJ, Giovannucci E, Ma J, Fuchs C, Hunter DJ (2005) APC Asp1822Val and Gly2502Ser polymorphisms and risk of colorectal cancer and adenoma. Cancer Epidemiol Biomarkers 14: 863-870

Wang L, Habuchi T, Mitsumori K, Li Z, Kamoto T, Kinoshita H, Tsuchiya N, Sato K, Ohyama C, Nakamura A, Ogawa O, Kato T (2003a) Increased risk of prostate cancer associated with AA genotype of cyclin D1 gene A870G polymorphism. Int J Cancer 103: 116-120

Wang L, Habuchi T, Takahashi T, Mitsumori K, Kamoto T, Kakehi Y, Kakinuma H, Sato K, Nakamura A, Ogawa O, Kato T (2003b) Cyclin D1 gene polymorphism is associated with an increased risk of urinary bladder cancer. Carcinogenesis 23: 257-264
Wang R, Zhang JH, Li Y, Wen DG, He M, Wei LZ (2003c) The association of cyclin D1 (A870G) polymorphism with susceptibility to esophageal and cardiac cancer in north Chinese population. Zhonghua Yi Xue Za Zhi 83: $1089-1092$

Weinstein IB, Begemann M, Zhou P, Han EK, Sgambato A, Doki Y, Arber N, Ciaparrone M, Yamamoto H (1997) Disorders in cell circuitry associated with multistage carcinogenesis: exploitable targets for cancer prevention and therapy. Clin Cancer Res 3: 2696-2702

Willett WC, Sampson L, Stampfer MJ, Rosner B, Bain C, Witschi J, Hennekens CH, Speizer FE (1985) Reproducibility and validity of a semiquantitative food frequency questionnaire. Am J Epidemiol 122: 51 - 65

Wolf AM, Hunter DJ, Colditz GA, Manson JE, Stampfer MJ, Corsano KA, Rosner B, Kriska A, Willett WC (1994) Reproducibility and validity of a self-administered physical activity questionnaire. Int J Epidemiol 23: 991- 999

Zafonte BT, Hulit J, Amanatullah DF, Albanese C, Wang C, Rosen E, Reutens A, Sparano JA, Lisanti MP, Pestell RG (2000) Cell-cycle dysregulation in breast cancer: breast cancer therapies targeting the cell cycle. Front Biosci 5: D938-D961

Zhang J, Li Y, Wang R, Wen D, Sarbia M, Kuang G, Wu M, Wei L, He M, Zhang L, Wang S (2003a) Association of cyclin D1 (G870A) polymorphism with susceptibility to esophageal and gastric cardiac carcinoma in a northern Chinese population. Int J Cancer 105: $281-284$

Zhang YJ, Chen SY, Chen CJ, Santella RM (2003b) Polymorphisms in cyclin D1 gene and hepatocellular carcinoma. Mol Carcinogen 33: 125-129

Zheng Y, Shen H, Sturgis EM, Wang LE, Eicher SA, Strom SS, Frazier ML, Spitz MR, Wei Q (2001) Cyclin D1 polymorphism and risk for squamous cell carcinoma of the head and neck: a case-control study. Carcinogenesis 22: $1195-1199$

Zhou Q, Hopp T, Fuqua SA, Steeg PS (2001) Cyclin D1 in breast premalignancy and early breast cancer: implications for prevention and treatment. Cancer Lett 162: 3-17 